\section{Infección aguda por el virus de la inmunodeficiencia humana}

\section{Sr. Director:}

La primoinfección por el virus de la inmunodeficiencia humana, se define como el conjunto de fenómenos inmunológicos y virológicos que se desarrollan desde el momento en que el individuo se infecta por el virus, hasta que la viremia y el recuento de linfocitos CD4 en sangre periférica se estabiliza.

El conjunto de síntomas y signos que pueden aparecer durante la primoinfección se conoce como síndrome retroviral agudo o infección aguda por el virus de la inmunodeficiencia humana (VIH) (1).

A las pocas horas de producirse el contagio, el virus emigra a los órganos linfoides secundarios, especialmente a los linfocitos de la pared intestinal y también a los órganos linfoides primarios (timo), donde se replicará muy activamente (2). Posteriormente se producirá una elevación marcada de la viremia y un descenso que puede ser en ocasiones muy importante de los linfocitos CD4 en sangre periférica.

Más adelante se produce una respuesta inmune humoral y celular y también una disminución de las células susceptibles de ser infectadas que terminaran controlando la infección a las 12 semanas, coincidiendo con la resolución del síndrome retroviral agudo $(1,3)$.

En más del $50 \%$ de los pacientes, el síndrome retroviral agudo pasará inadvertido, dado lo poco específico del cuadro clínico, su curso habitualmente benigno y la escasa frecuencia de hospitalización de los pacientes, por lo que se requiere un elevado nivel de sospecha clínica. Sin embargo el diagnóstico precoz es muy importante, debido al riesgo de infección de otras personas en esta fase, además si se establece el diagnóstico, se seguirá de un seguimiento clínico e inmunovirológico y en ocasiones especiales se puede ensayar un tratamiento con fármacos antirretrovirales en el contexto de un ensayo clínico (4).

El cuadro clínico se presenta a las 2-4 semanas desde el momento de la infección y se parece a una mononucleosis infecciosa, observándose fiebre, adenopatías, faringitis, exantema, artromialgias y menos frecuentemente manifestaciones neurológicas, sobre todo cefalea, meningitis aséptica y radiculitis; manifestaciones digestivas, fundamentalmente náuseas y vómitos, a veces diarrea y en ocasiones candidiasis esofágica (5). Excepcionalmente puede aparecer neumonía por Pneumocistis jiroveci, cuando en los casos en que existe una gran disminución de los linfocitos CD4 (1).

Dado que en la primera fase las pruebas serológicas pueden ser negativas o de difícil interpretación, es necesario demostrar la presencia en sangre de estructuras antigénicas (antígeno p24) o genómicas del virus, determinando el número de copias de ARN (carga viral), que es la técnica de elección en esta fase, encontrándose altos niveles de replicación (6).

Por su escasa frecuencia, nos parece interesante presentar el caso de un paciente diagnosticado de primoinfeción por el virus de la inmunodeficiencia humana en nuestro hospital.

Varón de 31 años de edad, con antecedentes personales de tabaquismo de 20 cigarrillos al día, bebedor de 20 gramos de alcohol al día, no adicto a drogas por vía parenteral, trabaja en hostelería y dice ser homosexual.

Consultó por un cuadro de una semana de evolución de fiebre que en ocasiones alcanzaba $40^{\circ} \mathrm{C}$ y tenía un predominio vespertino, acompañada de artromialgias y odinofagia. No tos, ni alteraciones gastrointestinales.

En la exploración destacaba faringe enrojecida sin datos de candidiasis oral, algún afta bucal; múltiples adenopatías laterocervicales de un tamaño aproximado de 1 centímetro. Auscultación cardiaca y pulmonar normales. Abdomen: blando, depresible, no doloroso, no organomegalias.

Laboratorio: Hemograma: 2.600 leucocitos con 1.700 neutrófilos, hemoglobina de 12,3 g/dl, 57.000 plaquetas; bioquímica, destacaba GOT de 163 U/L, GPT de 224 U/L, GGT de 374 U/L, LDH: 556 U/L. Serología HIV por EIA. Negativa.

Radiografía de tórax normal. Ecografía abdominal: Hígado aumentado de tamaño de ecogenicidad homogénea, porta de calibre normal, ligera esplenomegalia homogénea.

En paciente se citó para estudio en consultas, pero dos semanas después consultó al presentar un cuadro compatible con parálisis facial periférica izquierda. No tenía fiebre ni odinofagia y el resto de la exploración física fue similar a la referida anteriormente, iniciándose tratamiento con corticoides.

Se recibieron los resultados solicitados inicialmente que mostraron una serología a citomegalovirus IgG positiva e IgM negativa, serología a toxoplasma IgG e IgM negativas, Epstein-Barr, Ig G positiva e IgM negativa. La serología al virus B y $\mathrm{C}$ fueron negativas.

En el hemograma, existían 7.500 leucocitos con 2.800 neutrófilos, hemoglobina de 12,3 gramos/dl y 152.000 plaquetas y en la bioquímica, GOT de $41 \mathrm{U} / \mathrm{L}$, GPT de $65 \mathrm{U} / \mathrm{L}$.

Una determinación de antígeno p24 fue positiva a las 4 semanas de la consulta inicial y se negativizó a las 12 semanas. Una nueva serología frente al virus de la inmunodeficiencia humana fue positiva por EIA a las 4 semanas de la primera consulta, confirmada posteriormente por Western-blot (immunoblotting). Una determinación de linfocitos CD4 a las 4 semanas de la primera consulta mostró un resultado de 493 células/ml y la carga viral fue de 420.000 copias $/ \mathrm{ml}$

Tras realizar diversa consultas, se decidió no realizar tratamiento con fármacos antirretrovirales.

El paciente siguió tratamiento en rehabilitación, efectuándose electroestimulación del nervio facial. Se continuaron revisiones en la consulta monográfica de HIV de nuestro centro, a los 4 meses los CD4 eran de 554 y a los 8 meses de 915 células $/ \mathrm{ml}$.

Posteriormente el paciente no volvió a acudir a nuestro hospital, perdiéndose el seguimiento.

\section{F. Marcos Sánchez, M. I. Albo Castaño, F. Árbol Linde, S. Casallo Blanco, D. Joya Seijo, P. del Valle Loarte}

Servicio de Medicina Interna. Hospital Nuestra Señora del Prado. Talavera de la Reina. Toledo

1. Leal M, Pulido I. Cuándo sospechar una primoinfección por el VIH. JANO 2006; 1604: 56-60.

2. Mehandru S, Tenner-Racz K, Racz K, Markowitz M. The gastrointestinal tract is critical to the pathogenesis of acute HIV-1 infection. J Allergy Clin Immunol 2005; 116: 419-422.

3. Phillips AN. Reduction of HIV concentration during acute infection: independence from a specific immune response. Science 1996; 271 : 497499.

4. Pilcher CD, Eron JJ, Galvin S, Gay C, Cohen MS. Acute HIV revisited: new opportunities for treatment and prevention. J Clin Invest 2004; 113 : 937-945.

5. Pedersen C, Getstoft J, Lindhart BO, Sindrup J. Candida esophagitis associated with acute human immunodeficiency virus infection. J Infect Dis 1987; 156: 529-530.

6. Stramer SL, Glynn SA, Kleinman SH. Detection of HIV-1 and HCV infections among antibody-negative blood by nucleic acid-amplification testing. N Engl J Med 2004; 351: 760-768. 